\title{
Advancing Ethical Principles for Non-Invasive, Respectful Research with Nonhuman Animal Participants
}

\author{
Lauren E. Van Patter \\ Department of Geography and Planning, Queen's University, \\ Kingston, Ontario, Canada \\ lauren.vanpatter@queensu.ca
}

Charlotte Blattner

Harvard Animal Law \& Policy Program, Harvard Law School, Cambridge, MA

\begin{abstract}
Animal studies scholars are increasingly engaging with nonhuman animals firsthand to better understand their lifeworlds and interests. The current ${ }_{3} \mathrm{R}$ framework is inadequate to guide respectful, non-invasive research relations that aim to encounter animals as meaningful participants and safeguard their well-being. This article responds to this gap by advancing ethical principles for research with animals guided by respect, justice, and reflexivity. It centers around three core principles: non-maleficence (including duties around vulnerability and confidentiality); beneficence (including duties around reciprocity and representation); and voluntary participation (involving mediated informed consent and ongoing embodied assent). We discuss three areas (inducements, privacy, and refusing research) that merit further consideration. The principles we advance serve as a starting point for further discussions as researchers across disciplines strive to conduct multispecies research that is guided by respect for otherness, geared to ensuring animals' flourishing, and committed to a nonviolent ethic.
\end{abstract}

\section{Keywords}

research ethics - animal studies - ethics protocol - animal research - non-invasive animal participants - representation - reciprocity 
There is a growing trend among animal studies researchers to engage with nonhuman animals (hereafter: animals) firsthand to acknowledge their agency and subjectivities and speak to their interests. In doing so, social scientists find themselves conducting fieldwork with animals, which raises a number of ethical questions that have not been sufficiently addressed in the literature, including: how can we design methods in a way that encounters animals as research participants, respects their interests, and safeguards their well-being? How can we anticipate and mitigate possible harms in advance?

There is a scarcity of information guiding the design of ethics protocols for research with animals, and fundamental gaps in the procedural structures of ethics reviews. Research Ethics Boards (REBs) do not review research conducted with animals, and Animal Care Committees (ACCs) take an instrumental, anthropocentric view wherein animals are treated as research objects whose use is justified based on benefits to humans, science, other animals, or broader taxa (Cojocaru \& van Gall, 2019). ACC Animal Use Protocols center on welfare and humane use, taking the ${ }_{3} \mathrm{R}$ Principle as their primary framework: replace, reduce, and refine (Blattner, 2019). The framework engages cost-benefit analyses (СвAs), and assessments of whether knowledge gained merits use, or whether animals should be used at all, are rarely engaged in existing review processes (Orlans, 2008). As a result, "animal ethics revolves, in most cases, around a presumed 'disposable' animal life" (Gillespie \& Collard, 2015, p. 205).

While these shortcomings can and should be challenged in invasive and non-invasive research, we focus on the second strand, where "the lack of a relevant ethical review process for multispecies field research serves to further subordinate meaningful discussion about the ethics of animal research practice in non-experimental social science" (Collard, 2015, p. 135). Recent efforts across a number of disciplines have begun to respond to this gap. Kantin and Wendler (2015) discuss both welfare- and agency-based considerations for the implementation of assent and dissent in research with animals. Mancini (2017) advances an animal-centered framework based on mediated and contingent consent for research on animal-computer interaction. Kuhl (2011) considers the ethical implications of how animals are represented in educational research. Most comprehensively, Tumilty et al. (2018) advance ethical practices based on a capabilities approach in the context of animal-assisted interventions and activities. Their discussion draws on human research ethics protocols and centers on four principles: autonomy, beneficence, maleficence, and justice. Although these efforts have made important contributions that are mobilized herein, they are situated within specific sub-disciplines, and a universal framework for non-invasive research with animal participants has yet to be advanced. 
The aim of this article is to present some preliminary considerations for designing (less speciesist) ethics protocols for non-invasive research programs with animal participants. It is intended to inform research which engages with animals in a respectful manner, meaning it acknowledges animals as agents and subjects, and seeks to create solidarity in resistance to intersecting systems of domination. It is not intended for use in research which has as its aim to improve knowledge about or welfare of animals in order to facilitate their ongoing commodification, instrumentalization, or exploitation.

Our protocol advances three core principles, each with several (nonexhaustive) sub-considerations: non-maleficence (vulnerability, confidentiality), beneficence (reciprocity, representation), and voluntary participation (mediated informed consent and ongoing embodied assent). These principles represent a starting point for developing more comprehensive ethics protocols for research with animals. Additional considerations and remaining questions are highlighted in the final sections, which we hope will catalyze further discussion.

\section{Preliminary Considerations}

\section{Overarching Approach}

The principles delineated herein are founded on the conviction that ethical research relations with animals must encounter individuals as subjects of their own lifeworlds and co-creators of knowledge. This challenges traditional binary thinking that positions humans as active creators of knowledge and animals as passive objects to be used in the creation of knowledge. The resultant instrumentalization of animals has been challenged from a range of ethical traditions, including utilitarian (e.g., Singer, 1977), rights-based (e.g., Regan, 2004), and feminist traditions (e.g., Donovan \& Adams, 2007). This protocol takes an integrative approach in order to be relevant to researchers working within a range of traditions.

This article advances that a practical starting point for developing a protocol for respectful research with animals is to build off of frameworks that guide research with humans. We therefore draw on the Canadian Tri-Council Policy Statement for the Ethical Conduct for Research Involving Humans (TCPS2 ["The Agencies"], 2014) to explore the ways in which these principles could be applied, modified, and extended in research with animals. The TCPS 2 (2014) is founded on the three core principles of respect for persons, concern for welfare, and justice. Although these are important considerations for research with animals, they are broad concepts not easily operationalizable in 
a concrete fashion. We therefore use these as background principles for three more specific and applicable guiding principles: non-maleficence, beneficence, and voluntary participation.

\section{Justice and Respect}

Research with animals must at all times adhere to the principles of respect and justice. Respect recognizes animals as intentional beings with lives as individuals and members of their communities. Justice requires that animals be treated respectfully not merely on the basis of charity; they must be fully respected on the basis of principles that are inalienable and justiciable (see Donaldson \& Kymlicka, 2016; Garner \& O'Sullivan, 2016). Justice also demands that animals be treated fairly and equitably. Fairness entails treating all research subjects with full and equal respect and concern. Equity entails "distributing the benefits and burdens of research participation in such a way that no segment of the population is unduly burdened by the harms of research or denied the benefits of the knowledge generated from it" (TCPS2, 2014, p. 8).

\section{Power Relations, Positionality, Reflexivity}

Even when solely observing an animal, researchers cannot operate as valueneutral bystanders. Researchers inevitably establish a relation with animals and must take responsibility for the outcomes of this relation, acknowledging, the important power differentials at play (Malone et al., 2010). Researchers have the power to decide which questions get asked, how findings are interpreted, and how animals are represented. Within our sociocultural context, animals' capacities are routinely underestimated, and they are at risk of being misinterpreted and misrepresented. Researchers must guard against interacting with and representing animals in ways that perpetuate relations of domination and marginalization. It is crucial to engage in reflexive practices and consider how these factors might influence the manner in which our research is conducted.

\section{Ethical Principles}

\section{Principle 1: Non-Maleficence}

We agree with Tumilty et al. (2018) that non-maleficence ought to be the first principle guiding research with animals and take precedence over all others. Non-maleficence means that no animal should be harmed in research for the benefit of humans, other animals, or broader taxa, and all possible measures should be taken to understand, prevent, and mitigate any potential harms that may result from research. If evidence emerges that the research is causing 
harms that were previously unforeseeable, the research must be terminated or modified. Harm is "anything that has a negative effect on the welfare of participants, and the nature of harm may be social, behavioural, psychological, physical or economic" (TCPS2, 2014, p. 21). Where there is uncertainty as to the extent or risk of possible harms, researchers should engage the precautionary principle and refrain from conducting proposed research until they have the ability to understand, prevent, and mitigate potential harms to animal participants. Two (non-exhaustive) areas merit consideration when applying the principle of non-maleficence: vulnerability and confidentiality.

\section{Vulnerability}

The TCPS2 (2014) describes vulnerability as "a diminished ability to fully safeguard one's own interests in the context of a specific research project. This may be caused by limited decision-making capacity or limited access to social goods, such as rights, opportunities and power" (p. 210). Assumptions about vulnerability should not be made on the basis of group membership, but rather on participants' circumstances in relation to the research. In line with critical disability theorists, Johnson (2013) advances a framework that rejects the problematic vulnerable/not-vulnerable dichotomy and acknowledges that each of us experiences "inherent vulnerability" stemming from our bodily needs and inevitable dependence on others. In addition, some individuals experience "situational vulnerabilities," which arise from particular circumstances. For example, some animals may have negative histories with humans which could increase the risks of possible harms due to interactions. Others may have limited opportunities to exhibit agency and to engage in decision-making, for instance, those in situations of confinement like shelters or rehabilitation centers.

Situational vulnerabilities may exist to different degrees and vary over time. It is important for researchers to recognize and respond to vulnerabilities in an adequate manner. For example, protocols for assessing assent and dissent in participants with mobility impairments would require that researchers take additional measures to ensure the well-being and interests of participants who may have limited opportunities to physically withdraw. Where possible, experts should be consulted to provide guidance on individuals' specific needs.

\section{Confidentiality}

Careful assessments of specific historical, political, and cultural contexts are needed to determine how information concerning animal participants may be used if it is made publicly available, and what the consequences of this might be. It is common practice in the biological sciences to keep the locations of endangered species confidential (Costello et al., 2016). This should be expanded 
to include the locations of all home ranges, colonies, den/nest sites, and other locations of animal participants in cases where there is the potential for antagonistic or exploitative human-animal interactions. Even when antagonism is not the concern, confidentiality can be relevant. As Collard (2014) notes, "fascination, love, and curiosity" may lead to "prolonged violence, suffering, and exploitation" (p. 162).

The need for confidentiality of factors beyond locational should be assessed on a case-by-case basis. Where animal participants may be known in the community, it may be appropriate to refrain from specifying identifiable characteristics such as name, heritage, family ties, health, etc. For example, disclosing the identity of animal residents in sanctuaries who have formerly been used in research or farming and were rescued by activists could pose a threat to the sanctuary and affected individuals. Where knowledge stemming from research could be used to vilify or otherwise marginalize individuals or groups, these findings should not be made public. Even when non-disclosure impacts research outcomes, safeguarding participants' well-being takes precedence over presenting unmediated findings.

\section{Principle 2: Beneficence}

Beneficence requires that animal participants benefit from research. Benefits can be direct (or immediate), such as positive experiences while participating, or indirect (or long-term), for instance, through improved livelihood opportunities as a result of research outcomes (Tumilty et al., 2018). In terms of direct benefits, many examples demonstrate that domesticated animals enjoy engaging with humans in a variety of ways (Donaldson \& Kymlicka, 2011; Jerolmack, 2009; Serpell, 1996; Willett, 2014). If a researcher is studying play and ensures voluntary participation, the animal may directly benefit from an enjoyable experience. Where animals live in conditions in which they may experience boredom, perhaps as inhabitants of rescue or rehabilitation centers that have limited resources to fully attend to animals' interests, engaging with researchers could be stimulating and beneficial.

For animals under the care of humans, knowledge generated about their circumstances, behaviors, experiences, and interests could result in improvements to their spaces, care practices, social contact, and human-animal communication. Indirect benefits include changes in human attitudes that result in better treatment or management/policy changes. Research on humanwildlife conflict, for instance, could contribute towards moving away from the use of harmful or lethal wildlife management tools in favor of more compassionate measures (e.g., Wallach et al., 2018). And where improved knowledge of animals factors into public education and awareness, research may contribute 
to a broader shift in human understandings and values, with the potential to replace speciesist or dominating attitudes with respect for otherness.

The principle of beneficence can be complex and challenging to apply. We acknowledge the risk of researchers holding unrealistic expectations of anticipated benefits for animals, particularly when benefits are long-term and researchers cannot guarantee their realization. Rather than an illusionary premise that at some point, through greater knowledge, benefits for animals will materialize, researchers need to make a concerted effort to think through and ensure that there will be tangible benefits. The nature of benefits depends on the context of each project, but there should be a high probability that benefits will manifest. We see two (non-exhaustive) areas that merit consideration when applying the principle of beneficence: reciprocity and representation.

\section{Reciprocity}

Many ethics protocols take а СвA approach wherein anticipated benefits are weighed against harms, but "by who's accounting," and "how do we prioritize competing values" (Malone et al., 2010, p. 782)? Where ACCs conduct СBAs, these committees might be in a better position to answer such questions due to their expertise, and opportunities for deliberation and contestation. But even when the criteria of сваs are detailed and multiple stakeholders review proposals, there is overwhelming evidence that proposals are approved as a rule, unless applications are sloppy (Miki-Kurosawa, Park, \& Hong, 2014; Gerritsen, 2015). Anticipated but vague benefits like economic prosperity and public health supersede individual animals' interests in life and bodily and mental integrity (Blattner, 2019). СвAs are thus "structurally biased against the animals" (Peters, 2016, p. 49). They are geared to advance human interests over animal interests and fail to take into account the qualities of each.

Rather than relying on СвA, this protocol focuses on reciprocity. Reciprocity centers on the view that "researchers and participants are equal, and that the research should be mutually beneficial, characterized by give-and-take" (Huisman, 2008, p. 374). Thus, animal participants contribute data that benefit researchers and add to the stock of human knowledge, and produced knowledge must benefit animal participants and more-than-human communities. In engaging reciprocal research practices, researchers replace "a colonialist approach of 'taking' for one of mutual exchange" (Huisman, 2008, p. 386).

Operationalizing reciprocity could take many forms. ${ }^{1}$ It could mean ensuring that results of research impact animal governance and policies in a

1 See, for example, Maiter et al.'s (2008) five guidelines for community-based participatory action research. 
manner that benefits animals by providing evidence-based recommendations to relevant stakeholders. It could mean designing a service research project, or giving back to animals' communities external to research (e.g., volunteering for an animal organization). If we acknowledge animals as co-creators of knowledge, we should consider including them as co-authors on publications (e.g., Savage-Rumbaugh et al., 2007). If co-authorship is not possible due to confidentiality concerns or institutional barriers, then the work of animal participants must at a minimum be acknowledged in publications. Though not of direct benefit to animals, this is part of broader efforts to acknowledge their work and challenge traditional views of animals as passive research objects.

\section{Representation}

Researchers have a responsibility to ensure that the way in which we represent animal participants benefits them. There are differences in communicating with animal versus human participants, and parts of animals' sensory, cognitive, and subjective experiences remain inaccessible to us. Inevitably, researchers must engage in forms of translation. Scholars from various disciplines highlight the dangers that emerge when we attempt to speak for others, particularly when relationships are marked by power discrepancies (Borkfelt, 2011; Sanders \& Arluke, 1993; Corman, 2016). This may deter us from trying to represent animals in the first place, but we feel, as others have argued, that a cautious and reflexive attempt at respectfully sharing their stories is better than not engaging their experiences (Hamilton \& Taylor, 2017; Kulick, 2017). The latter effectively silences animals as individuals and groups in social and cultural research, reinforcing human exceptionalism and animal marginalization.

Representational politics are well-acknowledged in the case of research with humans, and there are good reasons to believe they are equally applicable to animal participants (Kopnina, 2017). Critical ethnographers have asserted that writing is "world-making," and that researchers do more than simply represent realities, they create them (Saward, 2010; Smith, 2012). It is therefore a moral imperative to carefully consider which realities we bring into being through our writing, along with potential implications (Hamilton \& Taylor, 2017). Engaging with animals means that we stretch to the limit crucial questions of

how to understand and give voice to others or to experiences that seem impervious to our understanding; how to attend to difference without appropriating and distorting it; how to hear and acknowledge what it may not be possible to say.

WEIL, 2012, p. 7 
We as researchers have the "power to make visible or invisible" a decision that has a considerable impact on either facilitating or confounding understanding (Newton, 2009, p. 354).

Our representations can be harmful when they deny animals' agencies and interests, and passivize, objectify, ignore, or uncritically anthropomorphize individuals (Hamilton \& Taylor, 2017). Our discursive practices have material consequences in that our representations can "reinforce stereotypes, prejudices, and ultimately be used to justify continued oppression" (Kuhl, 2011, p. 108). Representations can benefit animals when they challenge human/animal dichotomies, highlighting intersubjectivity and shared capacities (Kuhl, 2011). Such efforts can make meaningful contributions to the extent that "[w] hat we assumed to be natural — human domination — is revealed instead to be manufactured, that is, ideological" (Fudge, 2002, p. 14).

The following are core steps researchers must take to ensure that representations are of benefit to animal participants:

Interpretation: employ both responsible anthropomorphism (Johnston, 2008) ${ }^{2}$ and consultation with experts (Meijer, 2013);

Representation: represent animals as subjects, with their own agencies, communities, and personalities, centering their stories, thoughts, feelings, and uniqueness (Freeman \& Merskin, 2016; Kuhl, 2011); provide detailed accounts of the context of interactions while also synthesizing information such that audiences have the best chance to interpret meaning in the intended manner (Newton, 2009); and

Avoid: using characterizations that perpetuate mechanomorphism (Crist, 1999), stereotypes, objectification, and victimization of animals (Freeman \& Merskin, 2016; Kuhl, 2011).

\section{Principle 3: Voluntary Participation}

Voluntary participation means that animals cannot be forced to participate in research. Our framework for voluntary participation combines ongoing embodied assent from animal participants and mediated informed consent from a human representative. This combined model is based on the premise that

2 Critical or responsible anthropomorphism advances that through empathy and shared experiences of inhabiting a body, humans can intuitively communicate with animals and apprehend their emotional and physical states (Greenhough \& Roe, 2011). Such approaches center on attunement, and empathetic and intuitive interpretations of another's embodied communications, including posture, movements, gestures, behaviors, and attitude (Shapiro, 1990; Warkentin, 2010). 
although many animals are able to understand, weigh, and communicate decisions in the context of research, if the broader context, purpose, and implications of research remain inaccessible to them, we cannot consider them to be informed consenters to the extent typically required. Individuals for whom the informed consent test is not appropriate should not, however, be excluded from participating in research, as this may run counter to the principle of justice (TCPS2, 2014, p. 43). Where research may have benefits, individuals should be provided with opportunities to meaningfully participate in knowledge creation regardless of their ability to provide informed consent.

\section{Mediated Informed Consent}

In research with humans for whom informed consent is not possible, the standard is to obtain informed consent from a personal consultee (MRC, 2007), legally authorized representative (WMA, 2019), or authorized third party (TCPS2, 2014) who considers the interests and well-being of the prospective participant. In research with animals, researchers should likewise seek mediated consent from a human representative who has the expertise and interest in considering individuals' well-being, preferences, and desires (Mancini, 2017). For wild animals, biologists, rehabilitators, veterinarians, or individuals working for wildlife NGOs could qualify as representatives.

For domesticated animals, it seems straightforward to appoint legal guardians. But this overlooks that many relationships between legal guardians and animals exist as a result of animals' property status, wherein relationships are shaped by incentives for humans to disregard the interest of animals, regardless of whether or not this is done with malicious intent. There is a broad spectrum of power relations in human-animal interactions (Tumilty et al., 2018). To assess whether human guardians are suitable to decide the best interest of animals, we propose that researchers employ: objective criteria (monetary interest, depth and nature of experience with an animal); triangulation of claims of various experts; and intuition (whether guardian/expert really cares about the animal). Where guardians do not pass this test, additional mediated consent should be sought from an expert who has knowledge of the individuals or species involved and has their best interests at heart (e.g., veterinarian, scholar with experience in animal research, animal rescue, or NGO worker).

\section{Ongoing Embodied Assent}

Mediated informed consent is necessary but not sufficient to ensure animals' voluntary participation. What is needed, in addition, is animals' ongoing embodied assent, "established through a non-human animal's willingness to undertake tasks associated with the research" (Tumilty et al., 2018, p. 403). 
Willingness is construed both positively and negatively: efforts must be made to communicate about research to the participants in a manner in which they can understand and respond; and individuals may at any point dissent from participation, which must result in stopping research procedures. Dissent is "an expressed objection, either verbal or behavioral, to what an individual is experiencing as a result of a research procedure" (Kantin \& Wendler, 2015, p. 461). Researchers must provide animals with a broad range of opportunities in which to show assent/dissent, including physical opportunities to retreat from interactions. In circumstances where participants have limited abilities to do so, careful consideration and consultation with experts will be required to ensure that participation is voluntary.

Assent/dissent should be interpreted to the best of the researcher's abilities using responsible, or critical, anthropomorphism (Burghardt, 2004; Johnston, 2008). By observing body language, we can often interpret how an individual is feeling. Facility with such interpretations will be strengthened through experience and background knowledge of species-specific communication. Researchers need to be open to communication, and if they sense that an animal participant is unhappy or does not wish to continue to interact or be observed, the researcher should interpret this as dissent. Many animal researchers employ the principle of voluntary participation, but details of protocols are often not formally codified (S. Brosnan, personal communication, August 28, 2018). There is not only ample opportunity, but compelling responsibility for the research community to further delineate the details of how voluntary animal participation can be operationalized, in terms of ensuring and interpreting ongoing assent and opportunities to dissent.

\section{Additional Considerations and Remaining Questions}

Along with the principles of non-maleficence, beneficence, and voluntary participation, we advance the following considerations as open questions to the research community that merit further discussion: inducements, privacy, and refusing research.

\section{Inducements}

Is the provision of inducements, such as food, ever appropriate in research with animal participants? Inducements should not be confused with the standard practice in invasive research of withholding food, water, or social interaction to encourage participation. The research community widely engages in "positive reinforcement" as a means to make animals comply with procedures 
that they would otherwise not accept (Fenton, 2014, p. 136). This protocol would not apply to such research, and the research would not be condoned. We see inducements as extras that are offered above and beyond the daily practices of animals. Arguments against inducements include that it could be thought of as buying trust. Food inducements may cause dependency, lead to adapted preferences, or even learned helplessness (Fenton, 2014). Arguments supporting inducements include that with domesticated animals, the provision of food gifts can be a normal part of greeting rituals and building rapport. According to the TCPS2 (2014), "[i]n some cultures, the giving and receiving of gifts symbolizes the establishment of a relationship comparable to consent" (p. 46). Similarly, gifts of food can foster a positive social interaction with animal participants.

The question of inducements should be assessed in a context-dependent manner, considering individuals' circumstances and relationships with the researcher and humans more generally. According to the TCPS2 (2014), relevant considerations include "economic circumstances... the age and decisionmaking capacity of participants, the customs and practices of the community, and the magnitude and probability of harms" (p. 27). Decisions should be made in consultation with the individuals from whom mediated consent is sought. We propose that when in doubt, the more cautious approach is to refrain from offering inducements, so as to avoid compromising voluntary participation.

\section{Privacy}

Does the use of cameras or firsthand observation in research with animals violate their privacy? Privacy is "[a]n individual's right to be free from intrusion or interference by others" (ТСP 2, 2014, p. 208), and it is difficult to assess if harm is caused when animals have no knowledge they are being observed. Mills (2010) advances an approach accepted in the human context: the public/ private distinction. Individuals have a right to consent when observed or filmed in private spaces, whereas in public spaces, there is no such duty. The author similarly advances that animals' "private" spaces such as nests, dens, etc. are off limits, but they can be filmed when "they roam plains and deserts ... which take place in locations which include many other species, and in which the animal being filmed makes no explicit attempt not to be seen" (Mills, 2010, p. 198).

This aligns with the TCPS2 (2014), which specifies that observational research in public spaces where there is no expectation of privacy does not require consent. Though this narrows down the problem, it leaves many questions unanswered: What constitutes public versus private spaces for animals? Would mounting cameras in animals' spaces-something we would not 
consider acceptable for humans-reinforce relations of domination and our control over their spaces? Until these questions have been subject to greater discussion, we must either rely on the principle of reciprocity or refuse to conduct research about which we are unsure of possible implications.

\section{Refusing Research}

One of the most challenging questions for researchers to address is when to abstain from conducting research in the first place. This question has arisen in the human research context, demonstrated in Tuck and Yang's (2015) argument that refusal in research "attempts to place limits on conquest and the colonization of knowledge by marking what is off limits" (p. 225). Similarly, in research with animals, researchers should ask themselves hard questions when it comes to the types of knowledges generated and how they are likely to be mobilized. These issues are beginning to be addressed in the animal research community, usually framed as concerns both for the material impacts of human interactions with wild animals in research and as a result of the power operations at play. For instance, Malone et al. (2010) challenge the assumption in primatology that "knowing more" is "inherently good" (p. 780), and suggest that researchers "reduce the number of studies, especially those that require new habituation efforts" (p. 783).

Collard (2015) similarly writes that ethical research decisions will involve "choosing, at times, not to enter into proximate physical encounters, to let an animal be unencounterable" (p. 163). Researchers must decide when their studies have a real potential to change animals' lives for the better and when the ethical choice is to refrain from engaging. While there are no simple frameworks to guide such decisions, we advocate for a both reflexive consideration and honest discussion with other researchers about likely outcomes and intentions, and in particular whether the research is guided by commitments to justice and solidarity, or if it risks legitimating or reproducing relations of domination.

\section{Limitations of Ethics Protocols and Critical Reflections}

Although we feel advancing principles for respectful research with animal participants is an important contribution to efforts in animal studies, we acknowledge such an approach has limitations. Others have argued that guidelines alone are insufficient, and that since "ethical decision-making is inherently and unavoidably imprecise and non-formulaic, we should guard against transmogrifying it into a formulaic exercise" (Vucetich \& Nelson, 2007, p. 1275). Critical 
geographers assert that applying the medical model of research governance to social scientific research establishes a rhetoric of accountability but effectively ignores, or even threatens, the various ethical and political tensions which may arise when conducting research (Dyer \& Demeritt, 2009). Rather than fostering genuine ethical research relations, the medical model risks "cultivat[ing] cultures of counterfeit practice" (Halse \& Honey, 2005, p. 2142). What is needed is a reflexive "ethics in practice" to capture the importance of situated ethical relations (Guillemin, 2004, p. 262). The nature of such ethical engagements cannot be planned for, but we contend that principles such as those outlined herein serve as important starting points for thinking through possible ramifications of research, and cultivating an improved ability to respond to dilemmas which may emerge during fieldwork.

It has also been argued that REB frameworks are rooted in modern western understandings which are narrowly focused on individualized autonomous subjects, and carry with them a deeply problematic neocolonial paternalism, particularly when applied to research with non-western and Indigenous communities (Dyer \& Demeritt, 2009; Tuck \& Guishard, 2013). ${ }^{3}$ In this context, we risk imposing on animals a particular human-centered framework that perpetuates injustices and invites paternalistic attitudes? How we can move beyond narrow humanist understandings of ethics while operating within human-created research programs and institutions is a complicated question.

According to Chakrabarty (200o), we must perform a double task, which is thinking in humanistic categories and simultaneously questioning and reconstructing these. Chagani (2018) points out that although conventional humanist frameworks ignore animals' agency and subjective experiences, more radical posthumanist approaches can risk dispensing with responsibilities. We consider these debates immensely important, but also extremely delicate, generating a range of complex questions: What would a decolonial, feminist, posthumanist approach to research ethics look like? Can there ever be a framework that is just if it is entirely set up by the dominant group? How can we recognize our ethical obligations to relationally-embedded animal participants and their

3 It has also been argued that REBs themselves are complicit in legitimizing settler colonial projects under the veneer of science (Tuck \& Guishard, 2013). Decolonizing animal research will involve critically reflecting on the ways in which researchers' assumptions may perpetuate colonial logics, and drawing respectfully on other ways of knowing and relating (Sundberg, 2014). 
communities without the risk of sacrificing the individual for the purposes of broader taxa? Addressing these questions is a key area of future discussion and development, and one we are committed to working towards.

\section{Conclusion}

The majority of research with animals is built on socio-ideological pillars which consider animals disposable and freely available for human benefit. Various projects in animal studies aim to counter these dynamics by establishing relations that are guided by respect for otherness, geared to ensure animals' flourishing, and committed to a non-violent ethic. Many such scholars have qualms about conducting research with animals while lacking an adequate ethics protocol. We advanced principles for designing ethics protocols for noninvasive research with animal participants that mark a departure from current speciesist ACC conventions and are guided by respect, justice, and reflexivity. The three core principles are: non-maleficence (including duties of vulnerability and confidentiality), beneficence (including duties of reciprocity and representation), and voluntary participation (mediated informed consent and ongoing embodied assent). The brief discussions of inducements, privacy, and refusing research highlight just three of the many areas that merit further consideration as researchers strive to foster ethical relations with animal participants while learning about their lifeworlds and experiences and working to promote their interests.

As long as the status quo in research institutions remains within a welfarist ${ }_{3} \mathrm{R}$ framework, scholars who want to engage in respectful, non-invasive research with animals will need to adopt such protocols on a voluntary basis. Researchers could consider preparing an ethics protocol based on principles such as those outlined herein and submitting them for review by an arm'slength committee. It is our vision that in the future, a network of researchers willing to serve on voluntary review committees could be formed such that animal studies scholars could receive comments on proposed non-invasive research with animal participants. As researchers increasingly choose to adopt such processes voluntarily, it is our hope that institutional review boards will similarly move towards more comprehensive ethical considerations for noninvasive, respectful research with animals. This article will serve as a useful starting point for future discussions of how multispecies researchers can design protocols that can be operationalized in a diversity of contexts, and effectively protect the interests and promote the flourishing of animal participants. 


\section{Acknowledgments}

The authors would like to thank Alice Hovorka, Rosemary Collard, Chris Darimont, and Suzanne MacDonald for helpful discussions on this topic. Special thanks are owed to Will Kymlicka, Sue Donaldson, Darren Chang, and Omar Bachour for their constructive comments on an earlier draft. We express our deep appreciation to the Kingston Interspecies Community Research Group and the interspecies community at VINE Sanctuary for helping us think through our propositions.

\section{References}

Blattner, C. E. (2019). Rethinking the ${ }_{3}$ Rs: From whitewashing to rights. In K. Herrmann \& K. Jayne (Eds.), Animal experimentation: Working towards a paradigm change (pp. 168-193). Leiden: Brill.

Borkfelt, S. (2011). Non-human otherness: Animals as others and devices for othering. In S. Y. Sencindiver, M. Beville, \& M. Lauritzen (Eds.), Otherness: A multilateral perspective (pp. 137-154). Frankfurt a.M.: Peter Lang.

Bradshaw, G. A. (2010). An ape among many: Animal co-authorship and trans-species epistemic authority. Configurations, 18 (1-2), 15-30.

Burghardt, G. M. (2004). Ground rules for dealing with anthropomorphism. Nature, 430,15 .

Chagani, F. (2016). Can the postcolonial animal speak? Society \& Animals, 24 (6), 619-637.

Chakrabarty, D. (2000). Provincializing Europe: Postcolonial thought and historical difference. Princeton, NJ: Princeton University Press.

Cojocaru, A.-D., \& van Gall, P. (2019). Beyond plausibility checks: A case for moral doubt in review processes of animal experimentation. In K. Herrmann \& K. Jayne (Eds.), Animal experimentation: Working towards a paradigm change (pp. 289-304). Leiden: Brill.

Collard, R. C. (2014). Putting animals back together, taking commodities apart. Annals of the Association of American Geographers, 104 (1), 151-165.

Collard, R. C. (2015). Ethics in research beyond the human. In T. Perreault, G. Bridge, \& J. McCarthy (Eds.), The Routledge handbook of political ecology (pp. 127-139). London, UK: Routledge.

Corman, L. (2016). The Ventriloquist's burden. In J. Castricano \& L. Corman (Eds.), Animal subjects 2.o (pp. 473-512). Waterloo, ON: Wilfried Laurier University Press.

Costello, M. J., Beard, K. H., Corlett, R. T., Cumming, G. S., Devictor, V., Loyola, R., ... Primack, R. B. (2016). Field work ethics in biological research. Biological Conservation, 203, 268-271. 
Crist, E. (1999). Images of animals: Anthropomorphism and animal mind. Philadelphia: Temple University Press.

Donaldson, S., \& Kymlicka, W. (2011). Zoopolis: A political theory of animal rights. Oxford, UK: Oxford University Press.

Donaldson, S., \& Kymlicka, W. (2016). Rethinking membership and participation in an inclusive democracy. In B. Arneil \& N. J. Hirschmann (Eds.), Disability and political theory (pp. 168-197). Cambridge, UK: Cambridge University Press.

Donovan, J., \& Adams, C. J. (Eds.). (2007). The feminist care tradition in animal ethics: A reader. New York, NY: Columbia University Press.

Dyer, S., \& Demeritt, D. (2009). Un-ethical review? Why it is wrong to apply the medical model of research governance to human geography. Progress in Human Geography, $33(1), 46-64$.

Fenton, A. (2014). Can a chimp say "no"?: Reenvisioning chimpanzee dissent in harmful research. Cambridge Quarterly of Healthcare Ethics, 23 (2), 130-139.

Freeman, D., \& Merskin, C. (2016). Respectful representation: An animal issues style guide for all media practitioners. In N. Almiron, M. Cole, \& C. P. Freeman (Eds.), Critical animal and media studies: Communication for nonhuman animal advocacy (pp. 205-220). London UK: Routledge.

Fudge, E. (2002). A left-handed blow: Writing the history of animals. In N. Rothfels (Ed.), Representing animals (pp. 3-18). Bloomington: Indiana University Press.

Garner, R., \& O'Sullivan, S. (2016). Introduction. In R. Garner \& S. O'Sullivan (Eds.), The political turn in animal ethics (pp. 1-14). London, UK: Rowman and Littlefield International.

Gerritsen, V. (2015). Evaluation process for animal experiment applications in Switzerland. ALTEX Proceedings, 4 (1), 37-40.

Gillespie, K., \& Collard, R. C. (Eds.). (2015). Critical animal geographies: Politics, intersections and hierarchies in a multispecies world. London, UK: Routledge.

Greenhough, B., \& Roe, E. (2011). Ethics, space, and somatic sensibilities: Comparing relationships between scientific researchers and their human and animal experimental subjects. Environment and Planning D: Society and Space, 29 (1), 47-66.

Guillemin, M., \& Gillam, L. (2004). Ethics, reflexivity, and "ethically important moments" in research. Qualitative inquiry, 10 (2), 261-280.

Halse, C., \& Honey, E. (2005). Unraveling ethics: Illuminating the moral dilemmas of research ethics. Signs, 30, 2141-2162.

Hamilton, L., \& Taylor, N. (2017). Ethnography after humanism: Power, politics and method in multi-species research. London UK: Palgrave MacMillan.

Huisman, K. (2008). "Does this mean you're not going to come visit me anymore?": An inquiry into an ethics of reciprocity and positionality in feminist ethnographic research. Sociological Inquiry, 78 (3), 372-396. 
Jerolmack, C. (2009). Humans, animals, and play: Theorizing interaction when intersubjectivity is problematic. Sociological Theory, 27 (4), 371-389.

Johnson, J. (2013). Vulnerable subjects? The case of nonhuman animals in experimentation. Journal of Bioethical Inquiry, 10 (4), 497-504.

Johnston, C. (2008). Beyond the clearing: Towards a dwelt animal geography. Progress in Human Geography, 32 (5), 633-649.

Kantin, H., \& Wendler, D. (2015). Is there a role for assent or dissent in animal research? Cambridge Quarterly of Healthcare Ethics, 24 (4), 459-472.

Kopnina, H. (2017). Beyond multispecies ethnography: Engaging with violence and animal rights in anthropology. Critique of Anthropology, 37 (3), 333-357.

Kuhl, G. J. (2011). Representing animal-others in educational research. Canadian Journal of Environmental Education, 16, 106-122.

Kulick, D. (2017). Human-animal communication. Annual Review of Anthropology, 46, 257-378.

Lloyd, K., Wright, S., Suchet-Pearson, S., Burarrwanga, L., \& Country, B. (2012). Reframing development through collaboration: Towards a relational ontology of connection in Bawaka, North East Arnhem Land. Third World Quarterly, 33 (6), 1075-1094.

Maiter, S., Simich, L., Jacobson, N., \& Wise, J. (2008). Reciprocity: An ethic for community-based participatory action research. Action research, 6 (3), 305-325.

Malone, N. M., Fuentes, A., \& White, F. J. (2010). Ethics commentary: Subjects of knowledge and control in field primatology. American Journal of Primatology, 72, 779-784.

Mancini, C. (2017). Towards an animal-centred ethics for animal-computer interaction. International Journal of Human-Computer Studies, 98, 221-233.

Medical Research Council (MRC). (2007). MRC ethics guide 2007: Medical research involving adults who cannot consent. Retrieved April 10, 2018, from https://mrc.ukri .org/documents/pdf/medicalresearch-involving-adults-who-cannot-consent/.

Meijer, E. (2013). Political communication with animals. Humanimalia, 5 (1), 28-52.

Miki-Kurosawa, T., Park, J. H., \& Hong, C.-C. (2014). Laws, regulations, guidelines, and principles pertaining to laboratory animals in Far East Asia. In J. Guillén (Ed.), Laboratory animals: Regulations and recommendations for global collaborative research (pp. 268-295). San Diego, London, Waltham: Academic Press.

Mills, B. (2010). Television wildlife documentaries and animals' right to privacy.Journal of Media \& Cultural Studies, 24 (2), 193-202.

Newton, J. H. (2009). Visual representation of people and information: Translating lives into numbers, words, and images as research data. In D. M. Mertens \& P. E. Ginsberg (Eds.), The handbook of social research ethics (pp. 353-372). Thousand Oaks, CA: Sage.

Orlans, F. B. (2008). Ethical themes of national regulations governing animal experiments: An international perspective. In S. J. Armstrong \& R. G. Botzler (Eds.), The animal ethics reader (pp. 365-372). New York, NY: Routledge. 
Peters, A. (2016). Liberté, égalité, animalité: Human-animal comparisons in law. Transnational Environmental Law, 5 (1), 25-53.

Philo, C. (1998). Animals, geography, and the city: Notes on inclusion and exclusions. In J. Wolch \& J. Emel (Eds.), Animal geographies: Place, politics, and identity in the nature-culture borderlands (pp. 51-71). London, UK: Verso.

Regan, T. (2004). The case for animal rights (2nd ed.). Berkeley, CA: University of California Press.

Sanders, C. R., \& Arluke, A. (1993). If lions could speak: Investigating the human-animal relationship and the perspectives of nonhuman others. Sociological Quarterly, 34 (3), 377-39o.

Savage-Rumbaugh, S., Wamba, K., Wamba, P., \& Wamba, N. (2007). Welfare of apes in captive environments: Comments on, and by, a specific group of apes. Journal of Applied Animal Welfare Science, 10 (1), 7-19.

Saward, M. (2010). The representative claim. Oxford, UK: Oxford University Press.

Serpell, J. (1996). In the company of animals: A study of human-animal relationships. Cambridge, UK: Cambridge University Press.

Shapiro, K. J. (1990). Understanding dogs through kinesthetic empathy, social construction, and history. Anthrozoös, 3 (3), 184-195.

Singer, P. (1977). Animal liberation. Towards an end to man's inhumanity to animals. London, UK: Granada Publishing Ltd.

Smith, K. (2012). Governing animals: Animal welfare and the liberal state. Oxford, UK: Oxford University Press.

Sundberg, J. (2014). Decolonizing posthumanist geographies. Cultural Geographies, 21 (1), 33-47.

TCPS2 ["The Agencies"]. (2014). Tri-council policy statement: Ethical conduct for research involving humans. Retrieved April10, 2018, from https://ahrecs.com/resources /tri-council-policy-statement-ethical-conduct-for-research-involving-humans-2014.

Tuck, E., \& Guishard, M. (2013). Uncollapsing ethics: Racialized sciencism, settler coloniality, and an ethical framework of decolonial participatory action research. In T. M. Kress, C. S. Malott, \& B. J. Porfilio (Eds.), Challenging status quo retrenchment: New directions in critical research (pp. 3-27). Charlotte, NC: Information Age Publishing.

Tuck, E., \& Yang, K. W. (2014). R-words: Refusing research. In D. Paris \& M. Winn (Eds.), Humanizing research: Decolonizing qualitative inquiry with youth and communities (pp. 223-248). Thousand Oaks, CA: Sage.

Tumilty, E., Smith, C. M., Walker, P., \& Treharne, G. (2018). Ethics unleashed: Developing responsive ethical practice and review for the inclusion of non-Human Animal participants in qualitative research. In R. Iphofen \& M. Tolich (Eds.), The SAGE handbook of qualitative research ethics (pp. 396-410). Thousand Oaks, CA: Sage. 
Vucetich, J. A., \& Nelson, M. P. (2007). What are 6o warblers worth? Killing in the name of conservation. Oikos, 116 (8), 1267-1278.

Wallach, A. D., Bekoff, M., Batavia, C., Nelson, M. P., \& Ramp, D. (2018). Summoning compassion to address the challenges of conversation. Conservation Biology. doi: $10.1111 /$ cobi.13126.

Warkentin, T. (2010). Interspecies etiquette: An ethics of paying attention to animals. Ethics \& the Environment, 15 (1), 101-121.

Weil, K. (2012). Thinking animals: Why animal studies now? New York, NY: Columbia University Press.

Willett, C. (2014). Interspecies ethics. New York, NY: Columbia University Press.

World Medical Association (WMA). (2019). World Medical Association Declaration of Helsinki: Ethical principles for medical research involving human subjects. Retrieved December 3, 2018, from https://www.wma.net/policies-post/wma-decla ration-of-helsinki-ethical-principles-formedical-research-involving-human -subjects/. 